\title{
Detection of Building Damage Using Helmholtz Tomography
}

\author{
by M. D. Kohler, A. Allam, A. Massari, and F.-C. Lin
}

\begin{abstract}
High-rise buildings with dense permanent installations of continuously recording accelerometers offer a unique opportunity to observe temporal and spatial variations in the propagation properties of seismic waves. When precise, floor-by-floor measurements of frequency-dependent travel times can be made, accurate models of material properties (e.g., stiffness or rigidity) can be determined using seismic tomographic imaging techniques. By measuring changes in the material properties, damage to the structure can be detected and localized after shaking events such as earthquakes. Here, seismic Helmholtz tomography is applied to simulated waveform data from a high-rise building, and its feasibility is demonstrated. A 52-story dual system building - braced-frame core surrounded by an outrigger steel moment frame-in downtown Los Angeles is used for the computational basis. It is part of the Community Seismic Network and has a three-component accelerometer installed on every floor. A finite-element model of the building based on structural drawings is used for the computation of synthetic seismograms for 60 damage scenarios in which the stiffness of the building is perturbed in different locations across both adjacent and distributed floors and to varying degrees. The dynamic analysis loading function is a Gaussian pulse applied to the lowest level fixed boundary condition, producing a broadband response on all floors. After narrowband filtering the synthetic seismograms and measuring the maximum amplitude, the frequency-dependent travel times and differential travel times are computed. The travel-time and amplitude measurements are converted to shear-wave velocity at each floor via the Helmholtz wave equation whose solutions can be used to track perturbations to wavefronts through densely sampled wavefields. These results provide validation of the method's application to recorded data from real buildings to detect and locate structural damage using earthquake, explosion, or ambient seismic noise data in near-real time.
\end{abstract}

Electronic Supplement: Table and figures describing nine additional velocity imaging tests that were run using the same procedure described in the main article.

\section{Introduction}

We show how approximating a building as a continuum allows us to image temporally varying gradients in building material properties using Helmholtz tomography. Representing a building as a continuum leads to convenient theory using the steady-state wave equation, or Helmholtz equation, to image variations in elastic properties. This allows us to solve the wave equation for heterogeneous spatial properties to investigate anomalous gradients in an objective approach. It also precludes the dependence of building damage detection on parameterized (modal) systems (Farrar and Worden, 2012, and references therein) that could bias the estimation of the damage locations and spatial wavelengths. Solutions to the wave equation for heterogeneity in material properties in theory lead to better spatial resolution of damage localization. Moreover, dispersion properties can be measured in a flexible way that does not depend on a parameterized or analytical model of the building.

This study leverages the success of high-resolution imaging techniques applied to seismic array data to develop a propagating wave approach to detect and map damage in buildings via waveform feature extraction immediately after a major earthquake. We test the application of a waveform time-series-based damage detection technique not applied to buildings previously because before now, long-time-operational (order of years) seismic arrays in buildings have not provided the spatial sampling resolution to detect spatial and temporal variations in building response on a floor-by-floor scale. For example, permanently installed seismic arrays in structures in the United States operated by the California Strong Motion Instrumentation Program in cooperation with 
the U.S. Geological Survey usually provide single-channel data from multiple floors but not continuously or in real time (Center for Engineering Strong Motion Data, 2018, see Data and Resources). The few exceptions include the seismic arrays in the Atwood Building in Anchorage, Alaska (Celebi, 2006), Factor Building in Los Angeles, California (Kohler et al., 2007), Veterans Administration hospital buildings (Ulusoy et al., 2013), and Green Building in Cambridge, Massachusetts (Mordret et al., 2017), which are (or were) real time and dense, in at least one channel.

We are motivated by the 1994 Northridge earthquake, which highlighted a common type of unanticipated structural failure - a brittle fractured weld in beam-column connections - that is difficult to identify either visually or through localized ultrasonic testing (Youssef et al., 1995; Updike, 1996; Mahin, 1998; Roeder, 2000; Rodgers and Mahin, 2004, 2009). Post-Northridge analysis showed that weld fracture significantly decreases the ductility of tall steel buildings (Hall et al., 1995). The prevalence of fractured welds in mid- and high-rise structures shows how new computational tools that take advantage of next-generation seismic arrays can identify their occurrence after a large earthquake. This study numerically tests a damage detection method on computational finiteelement damaged model responses of a building that is also currently instrumented by a strong-motion network.

A large bulk of mechanical structure damage detection work uses analogous phenomena associated with guided elastic waves propagating along the structure's free surface boundaries to extract features (Farrar and Worden, 2007, 2012). One of the most predominant of these is the experimental generation and recording of Lamb waves, which has led to useful techniques to locate damage features in plates, shells, frames, and structural components associated with moving or rotating machinery (Farrar and Worden, 2012). Like the approach presented here, Lamb waves have wavelengths of the same order as the smaller dimension of the structure and wavespeeds that are dispersive. Lamb wave generation is usually produced by driving an actuator signal at specific frequencies and recording the response at an array of proximal receivers; thus, variations in propagating wave properties such as travel time, phase, amplitude, and reflections can be used to identify and locate damage-related features in the structure. However, Lamb waves are a combination of longitudinal and shear waves, but the approach presented here has its analogies in shear-wave (as opposed to compressional or longitudinal wave) seismic body waves; it furthermore does not depend on knowing or measuring the modal properties of the structure.

This study is a postevent, state-of-health approach that is optimally applied in the presence of dense array data and knowing pre-event wave propagation characteristics such as phase velocities and amplitudes. It does not depend on recording the transient signal during the damage event itself. This is different from the few unique exceptions such as the studies done by Dunand et al. (2004) and Rodgers and Celebi (2005), which involved analysis of transient signals recorded during damaging shaking caused by the 1994 Northridge earthquake.
Low-cost microelectromechanical systems (MEMS) technology sensors are now making it possible to instrument buildings on a floor-by-floor scale and to record continuous vibration data at high sampling frequencies of $200 \mathrm{~Hz}$ or higher. The Community Seismic Network (CSN) is one of these low-cost networks, expanding at a steady rate and now consisting of 900 active accelerometer sensors deployed in the urban region of the Los Angeles basin, including on multiple floors of buildings (Clayton et al., 2011, 2015; Kohler et al., 2013, 2014). Because the cost of the sensors is low, making them easy to install at high densities over small areas, it is critical to be able to interpret data recorded by the sensors in the face of continuously changing environments subjected to shaking and damage from earthquakes, natural hazards such as wind storms, and anthropogenic hazards such as explosions (Kohler et al., 2016). Community-hosted seismic arrays such as CSN are now making it possible to analyze vibration data on a small spatial scale because of the deployment of up to three triaxial accelerometers per floor. CSN instrumented more than 15 mid- and high-rise buildings that represent critical types of construction that are prone to damage during strong earthquake shaking. They include a 52-story steel moment and braced-frame, a 9-story steel moment frame with trusses and girders, a 15-story moment steel frame with concrete shear walls in the core, and a 12-story reinforced concrete with moment frames.

Seismic tomography techniques applied to arrays of seismometers deployed on the surface of the Earth have been successful for decades at imaging seismic velocities within the solid Earth, including large-scale mantle structure (e.g., French et al., 2013), magma chambers (e.g., Farrell et al., 2014), fault zones (e.g., Allam et al., 2014), and individual volcanoes (e.g., Lin et al., 2014). Recent instrumental and methodological advances have led to the application of seismic imaging techniques to spatially dense seismometer arrays (e.g., Lin et al., 2013; Ben-Zion et al., 2015; Hillers et al., 2016). In particular, ambient seismic noise (Shapiro et al., 2005) is now routinely used to construct surface waves and measure travel times between pairs of seismic stations via cross correlation (e.g., Lin et al., 2009; Porritt et al., 2011; Saygin and Kennett, 2012; Ward et al., 2013). These methods have also been applied to ambient vibrations from instrumented buildings (Prieto et al., 2010; Nakata and Snieder, 2014; Sun et al., 2017). Our study takes this one large critical step forward by presenting here a method that identifies and locates seismicvelocity changes in buildings; furthermore, we show how these velocity changes are related to small-scale (localized) material property changes (stiffness) due to damage.

A growing number of seismological studies demonstrate that interferometric methods applied to seismic array data show large-scale correlations between time-varying changes in seismic velocity and rock fracturing or coseismic (or postseismic) stress redistribution. For example, continuous seismic noise data recorded on the San Andreas fault have been used to monitor small variations in seismic velocity (Brenguier et al., 2008), and earthquake tomography has been 
applied to relate time-dependent variations in $V_{P} / V_{S}$ to abrupt changes in stress, fracturing, and active transport of fluids (Koulakov et al., 2013). Correlations have been found with precursory volcanic activity (Lecocq et al., 2014), annual oscillations in volcanic activity causing deformation (Hirose et al., 2017), and stress changes in rocks associated with geothermal reservoirs (Taira et al., 2015). In these studies, however, although small velocity changes can be detected, their sources are not precisely located and are only generally attributed to fault zone damage or stress change in rocks undergoing deformation.

Similar methods are now also being applied to seismic array datasets containing dynamic response of mid- and highrise structures to earthquakes, environmental conditions, and ongoing sources of low-level vibrations. Building on earlier work demonstrating the application of interferometric methods to mid-rise structures (Snieder and Safak, 2006; Kohler et al., 2007; Prieto et al., 2010), Nakata et al. (2013) show that deconvolution interferometry applied to earthquake data can be used to compute time-lapse changes in velocities, resulting in negative correlations between the maximum accelerations and wavespeeds in the building; they furthermore demonstrate that this method can separate the response of the building from soil-structure coupling effects. Nakata et al. (2015) found, from application of interferometric methods to 300 earthquakes before and after the 2011 Tohoku earthquake, that reductions in seismic velocities in a 10-story reinforced concrete building in Tokyo could be ascribed to damage in the building because no velocity reductions were found in the underlying near-surface soil layers. Most recently, Mordret et al. (2017) applied deconvolution interferometry to two weeks of ambient vibration data from a 20 -story reinforced concrete building, observing correlations between small wavespeed changes (including recoveries) and air humidity (as well as temperature to a lesser extent). Although it has been established that useful time-domain impulse response functions (or, more generally, transfer functions) can be obtained and monitored for timevarying changes of seismic velocities in buildings, techniques to compute precise locations of these changes for use in damage detection in buildings have remained elusive.

\section{Approach}

\section{Theory}

We show how solutions to the wave equation for mid- and high-rise buildings enable damage detection. The goal is to develop an approach for imaging structural defects in a system for which the eigenfunctions and eigenfrequencies either are not known or cannot be measured; if they are known, they can provide complementary information. Solutions to the relevant equations of motion describe longitudinal and shear waves that are body waves propagating throughout a continuum. The body-wave solutions describe wavefronts that travel throughout the structure and whose properties can be used to conduct nonparameterized system identification of the structure, as well as identify locations of perturbations to its properties (i.e., damage detection and localization). In this study, we focus in particular on vertical variations of elastic properties of buildings and their dynamic responses to external forces. We show that the assumption of a continuum is useful and appropriate for damage detection even if it is not correct on a structural element spatial scale (i.e., beam-column connection, section of column). Through this assumption, we will show how this leads to a second-order Helmholtz equation. The Helmholtz equation provides a straightforward way to solve for seismic-velocity variations in a building whose pre- and postdamage states have been determined by vibration time series recorded on seismic arrays.

To illustrate the parallels between a system approximated as lumped masses with massless supporting structures and a system represented as a continuum, we begin with the traditional force balance equation of motion used in structural dynamics. Consider the equation of motion for deformation of an idealized structure, for example, a steel moment-frame high-rise, subjected to external dynamic forces. External forces such as earthquake excitations $\boldsymbol{P}(t)$, are balanced with resisting forces:

$$
\boldsymbol{m} \frac{\partial^{2} u_{i}}{\partial t^{2}}+\boldsymbol{c} \frac{\partial u_{i}}{\partial t}+\boldsymbol{k} u_{i}=\boldsymbol{P}(t),
$$

whose individual components comprise an inertial force $\boldsymbol{m} \frac{\partial^{2} u_{i}}{\partial t^{2}}$, in which $\boldsymbol{m}$ is the mass matrix; damping forces $\boldsymbol{c} \frac{\partial u_{i}}{\partial t}$, in which $\boldsymbol{c}$ is the viscous damping coefficient; and the elastic (or inelastic) resisting forces (force-displacement relation, i.e., Hooke's law) $\boldsymbol{k} u_{i}$, in which $\boldsymbol{k}$ is the lateral stiffness matrix dependent on the dimensions of the structure and elastic modulus; $\frac{\partial^{2} u_{i}}{\partial t^{2}}, \frac{\partial u_{i}}{\partial t}$, and $u_{i}$ are acceleration, velocity, and displacement responses as a function of time $t$, with spatial coordinate index $i=1-3$ (e.g., Chopra, 2001). The equations of motion are typically expressed for single- or multiple-degree-of-freedom (MDOF) systems and are solved by assuming a lumped mass and massless supporting system, lumped stiffness, and an empirical form of damping such as Rayleigh damping.

When a nonparameterized method of measuring dynamic response is desired, it can be appropriate and useful to represent building structures as a continuum. This is possible because the low-frequency shear waves traveling through a building are influenced by the average properties of the building's structural and nonstructural elements, free surfaces, and empty volume (i.e., open air). They are not guided waves traveling solely along the surface or interior elements, such as the columns of the structure, and are not sensitive solely to each individual element. This approximation holds for systems in which the elastic moduli and density, that is, seismic velocities, vary smoothly in space (spatial variations in $\lambda, \mu$, and $\rho$ are small and gradual), and a solution to the wave equation can be found by plane waves that describe propagating wavefronts. Consider data-based observations that are made on a floor-by-floor spatial scale such as that made possible by community-hosted, triaxial, MEMS accelerometers deployed at a 
density of at least one per floor. When we consider small deformations (e.g., beam-column fractures or broken brace frames) in the path of propagating waves with wavelengths that are of the same order of magnitude as the spatial sampling scale (one floor or $\sim 5 \mathrm{~m}$ ), then treating a structure as a continuous medium leads to methods that are complementary to modal coordinate solutions of an MDOF system. We thus focus on the equations of motion in terms of stresses and strains for an elastic body acted on by internal and external forces. The corresponding equilibrium equation analogous to equation (1) is

$$
\rho \frac{\partial^{2} u_{i}}{\partial t^{2}}=f_{i}+\frac{\partial \sigma_{i j}}{\partial x_{j}},
$$

which defines the relationship between the inertial forces $\rho \frac{\partial^{2} u_{i}}{\partial t^{2}}$ with density $\rho$, body forces $f_{i}$, and stress gradients $\frac{\partial \sigma_{i j}}{\partial x_{j}}$ in spatial coordinates $x_{j}$ (e.g., Lay and Wallace, 1995), with summation convention $j=1-3$. Using stress-displacement relationships described by the continuum version of the elastic resisting force (Hooke's law)

$$
\sigma_{i j} C_{i j k l}=\varepsilon_{k l}
$$

in which $\sigma_{i j}$ is the second-order stress tensor, $C_{i j k l}$ is the fourth-order elastic modulus tensor, and $\varepsilon_{k l}$ is the second-order strain tensor and considering the strain-displacement relations relating stress to the elastic parameters, the $3 \mathrm{D}$ homogeneous vector equation of motion for a uniform, isotropic, linear elastic medium becomes

$$
\rho \ddot{\boldsymbol{u}}=(\lambda+\mu) \nabla(\nabla \cdot \mathbf{u})+\mu \nabla^{2} \mathbf{u}
$$

(Lay and Wallace, 1995). This is the 3D partial differential equation for displacements produced by an external force, with $\lambda=$ bulk modulus, $\mu=$ shear modulus, $\ddot{\boldsymbol{u}}=\frac{\partial^{2} u_{i}}{\partial t^{2}}, \nabla=3 \mathrm{D}$ partial derivative operator $\left(\frac{\partial}{\partial x_{1}}, \frac{\partial}{\partial x_{2}}, \frac{\partial}{\partial x_{3}}\right)$, and the dot indicates dot product. We will focus on solutions in orthogonal horizontal directions for a test bed structure consisting of a 52-story building.

The solutions to the 3D wave equation applied to building structures lead to seismic body waves with ray behavior that is analogous to seismic body waves propagating through the Earth's interior. Waves propagate along paths throughout the structure with propagation direction normal to the wavefronts. The physical and mathematical approximations that can be made for body-wave behavior are given by geometric ray theory in which waves in our building test bed are assumed to follow minimum-time paths, and perturbations in a building's elastic properties lead to changes in travel time. We take advantage of this property of geometric rays to show how solutions to an approximate wave equation might be used to identify and locate failure defects in buildings through the mapping of seismic-velocity perturbations that result from changes in travel time. Because we focus on low-frequency response as already described, this approach allows us to neglect the anisotropy that is certainly present in the high- frequency response of wave propagation on a structural element spatial scale.

The 3D wave equations as they apply to geometric ray theory for waves traveling at compressional or shear velocity $c_{p}(\boldsymbol{x})$ or $c_{s}(\boldsymbol{x})$ are

$$
\nabla^{2} \phi=\frac{1}{c_{P}^{2}(\boldsymbol{x})} \frac{\partial^{2} \phi}{\partial t^{2}}
$$

and

$$
\nabla^{2} \boldsymbol{\Psi}=\frac{1}{\left(c_{s}\right)^{2}} \frac{\partial^{2} \boldsymbol{\Psi}}{\partial t^{2}},
$$

with scalar potential $\phi$, vector potential $\Psi$, and total displacement $\boldsymbol{u}=\boldsymbol{\nabla} \phi+\nabla \times \boldsymbol{\Psi}$; these are an approximation to the equation of motion for heterogeneous media (Aki and Richards, 1980; Lay and Wallace, 1995; Shearer, 1999). We next consider a general functional form of displacement, $\varphi(x, t)$ given by plane-wave solutions

$$
\varphi(\boldsymbol{x}, t)=A(\boldsymbol{x}) e^{i( \pm \boldsymbol{k} \cdot \boldsymbol{x} \pm \omega t)}
$$

in which $A(\boldsymbol{x})$ is wave amplitude, $\omega$ is frequency, $\boldsymbol{k}$ is a vector pointing in the direction of wave propagation, and $\boldsymbol{x}$ is the 3D spatial coordinate vector (Lay and Wallace, 1995; Shearer, 1999). For the single-direction propagating wave of interest, for example, a shear-wave traveling vertically up a building, as considered in this study, this will be

$$
\varphi(\boldsymbol{x}, t)=A(\boldsymbol{x}) e^{i(\boldsymbol{k} \cdot \boldsymbol{x}-\omega t)}
$$

or

$$
\varphi(x, t)=\Omega(x) e^{-i \omega t},
$$

in which

$$
\Omega(\boldsymbol{x})=A(\boldsymbol{x}) e^{i(\boldsymbol{k} \cdot \boldsymbol{x})},
$$

and $\boldsymbol{x}$ defines the 3D position coordinates. Within a building, this would be the vertical, and two orthogonal horizontal directions; $|\boldsymbol{k}|=\frac{\omega}{c}$ are the wavenumbers. For a constant frequency, $\varphi(x, t)$ represents a complex, monochromatic wavetrain defined by amplitude and phase.

For heterogeneous media, it is more useful to describe the wave-position vector expression $\boldsymbol{k} \cdot \boldsymbol{x}$ in terms of a traveltime function that defines wavefront surfaces propagating with local slowness when this function is a constant. The travel times are often measured directly from the data, as is done in this study, to map seismic velocities. Replacing $\boldsymbol{k} \cdot \boldsymbol{x}$ with $\omega \tau(\boldsymbol{x})$, in which $\tau(\boldsymbol{x})$ is the travel time as a function of position, we obtain a similar expression to equation (10):

$$
\Omega(\boldsymbol{x})=A(\boldsymbol{x}) e^{i(\omega \tau(\boldsymbol{x}))} .
$$


Using this form for $\varphi$ in equation (9), the spatial and temporal parts of $\varphi$ can be separated upon insertion into the wave equation. Substituting equation (9) into equation (5), we obtain the time-independent (steady-state) wave equation with

$$
\nabla^{2} \Omega(x)=-\frac{\omega^{2}}{c^{2}(x)} \Omega(x),
$$

which is also referred to as the Helmholtz equation. Equating the real terms of each side of equation (12) using equation (11) yields

$$
\frac{1}{c^{2}(x)}=|\nabla \tau(x)|^{2}-\frac{\nabla^{2} A(x)}{A(x) \omega^{2}}
$$

(Lay and Wallace, 1995). Because small-scale properties are being averaged in the solution, we focus only on isotropic properties. If much higher frequency signals were resolvable in seismic array observations, then equations (5)-(13) would need to be modified to account for shear-wave anisotropy. A similar derivation can be carried out for shear waves using equation (6); thus, $c(x)$ represents either compressional or shear-wave velocity. This is the basis of the gradient calculations used to compute narrowband-filtered shear-wave velocities in this article.

This derivation is the same as the elastic Earth derivation applied to 2D surface waves (Lin and Ritzwoller, 2011). The right side of this equation containing the spatial Laplacian of the amplitude is referred to as the amplitude term and will be discussed in further detail later in the Results section. If we assume that the amplitude term is small and negligible (when $\omega$ is large), then equation (13) reduces to equation (14), a partial differential equation relating the seismic-wave travel times to phase velocity distribution, which is the eikonal equation used in seismology

$$
\frac{1}{c(x)}=|\nabla \tau(x)|
$$

(Lay and Wallace, 1995; Shearer, 1999). Waves propagating vertically up a building may be finite frequency in nature. Finite-frequency effects such as large lateral stiffness gradients and wave interference can produce nonnegligible bias on wave velocity estimates based on the eikonal equation (equation 14). However, if the wave amplitude varies smoothly on the single wavelength scale, then the second term on the right side of equation (13) may be insignificant.

Numerical Test Bed. Damage-detection calculations using the theory and approach described earlier were carried out with the aid of linear-elastic finite-element models of an existing building, developed based on detailed information contained in structural drawings provided by the building owner. The major structural and connection elements obtained from the drawings were modeled using object-based physical-member modeling, such as built-in steel sections and braces, to represent each component's effective level of stiffness and mass (ETABS, Computers and Structures, Inc.). The dynamic modeling software allows for static and dynamic linear simulations, as well as nonlinear analysis through insertion of nonlinear elements at locations of interest. The models were further refined by comparing recorded data from the building with simulated building response. Validation of the pre-event response baseline was also provided by the continuous ambient vibration sensing.

The test bed building consists of a 52-story ( +5 basement levels) high-rise building located in downtown Los Angeles (Fig. 1). This building's lateral dual system consists of a braced-frame core surrounded by a steel moment frame. The floor plans contain various setbacks and notches along the building's vertical profile. The building was constructed in 1988 and is used exclusively as an office building. The structural system consists of three major components: an interior concentrically braced core, outrigger beams spanning $\sim 12 \mathrm{~m}$ from the core to the building perimeter, and eight exterior outrigger columns (Fig. 1). The beams perform three primary functions: They support gravity loads, act as ductile momentresisting beams between the core and exterior frame columns, and enhance the overturning resistance of the building by engaging the perimeter columns to the core columns (Taranath, 1997). CSN has instrumented this building with one, and on a few floors two, triaxial sensors per floor, recording continuous acceleration waveform data. Several small- and moderate-size earthquake recordings made by CSN from this building, for example, the earthquake records shown in Figure 2, were used for model validation. The first few translational resonant frequencies of this building in the horizontal directions are $\sim 0.2,0.6$, and $1.2 \mathrm{~Hz}$ (Kohler et al., 2016).

Damage Scenario Generation Method. To generate the multiple building damage scenarios, we worked with a customized user interface to ETABS that computes modified linear finite-element models that contain user-specified damage scenarios. We used our undamaged finite-element model as the starting points with this interface to generate on the order of 60 new models of each building, each of which incorporates a realistic damage state that would be expected after strong shaking but that has not resulted in collapse or near collapse (Table 1).

The structure featured in this study offers different types of damage scenarios to explore in detail. The 52-story building's dual system provided an opportunity to test the interplay between beam-column connection failures and global buckling and tension rupture of the braced-frame components. In this study, brace frame damage is imposed on single and multiple floors distributed throughout the model (Table 1).

Travel Times. For each damage-state scenario listed in Table 1, displacements are computed by solving the linear equation of motion for the modified finite-element model with imposed damage. The external force applied at the base of the structure (lowest basement " $0 \mathrm{E}$ " level) is actually 
(a)

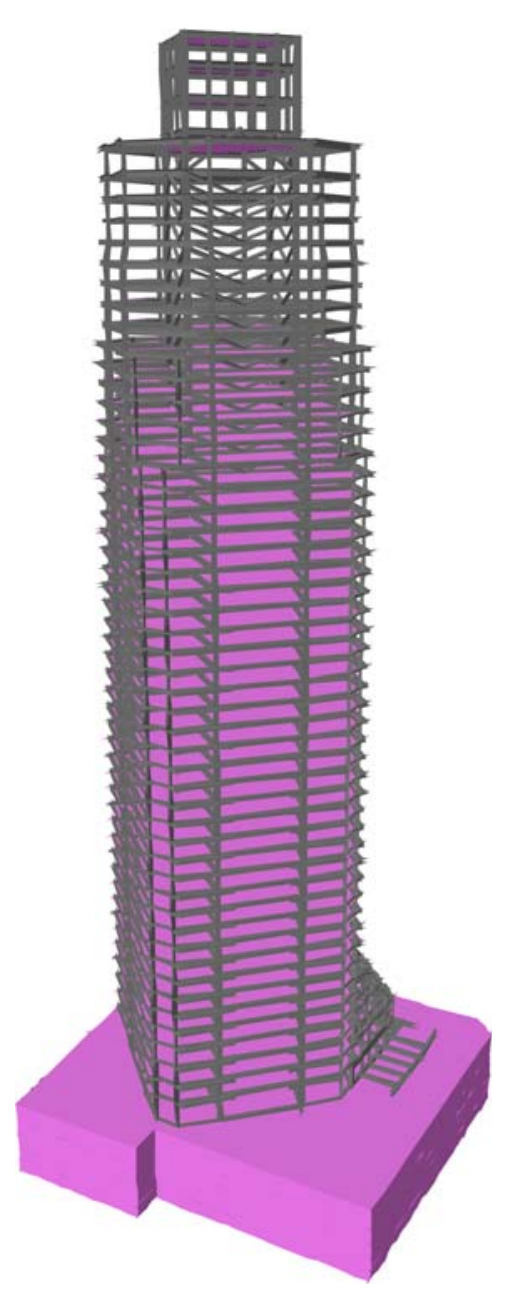

(b)

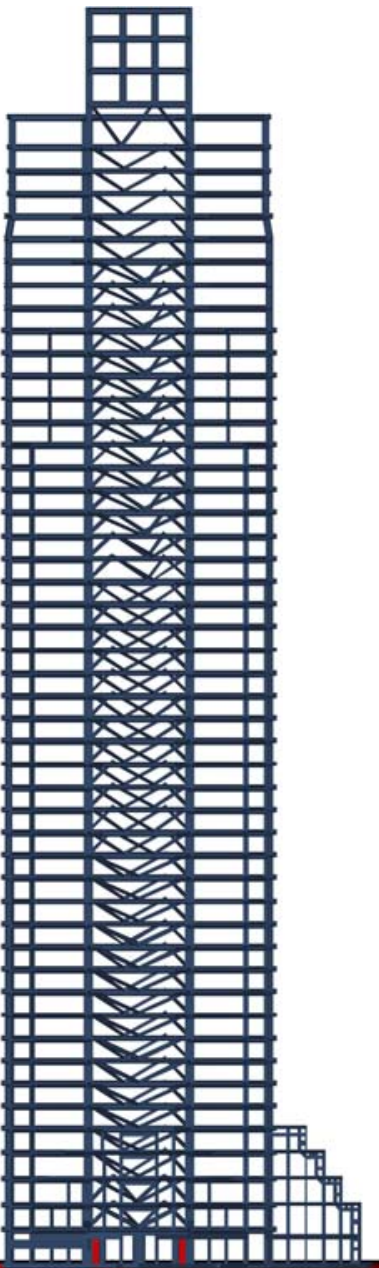

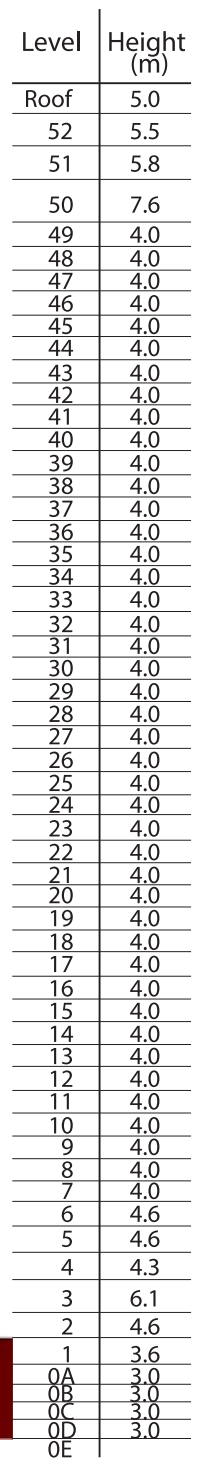

(c)

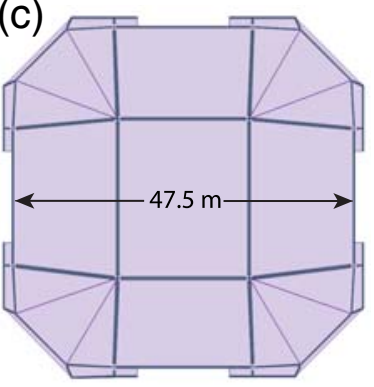

Figure 1. Finite-element model of the 52-story dual system building used in the dynamic analysis. (a) 3D frame image. Outrigger moment frames and diagonal braced core elements are shown in gray. Interior core is also shown in gray. (b) 2D profile showing frame and brace elements. (c) Plan view showing outrigger moment frame configuration typical of most floors. The color version of this figure is available only in the electronic edition.

acceleration derived from displacement represented by a Gaussian function with width equal to $T_{0} / 15$, in which $T_{0}$ is the fundamental period $(\sim 5.5 \mathrm{~s})$. The reason for using a relatively narrow Gaussian is to produce a broadband response similar to an earthquake (e.g., Aki, 1972), and it is a useful representation of the impulse response function of the building that could be computed from recorded data.

The simulated displacements consisting of each floor response (from the lowest basement $0 \mathrm{E}$ level to the 50th floor) are filtered using 39 separate Butterworth filters with center periods ranging from 1.0 to $20.0 \mathrm{~Hz}$, incremented at $0.5-\mathrm{Hz}$ intervals. A sigma (half-width) value equal to $10 \%$ of the central period is applied to obtain the narrowband-filtered numerical (synthetic) waveforms. The amplitude at each fre- quency is measured as the maximum of the real part of the Hilbert transform of the filtered waveform.

To measure the travel time as a function of propagation distance and frequency, we present two different methods representing different levels of prior knowledge about the system. The first method assumes that no characterization of the building's travel-time properties exists prior to the propagating wave, and the travel time is calculated by assuming the base floor as a reference waveform. The second method assumes some earlier undamaged characterization of the structure before the propagating wave, allowing the travel time to be calculated by comparison of damaged and undamaged cases. For the first method, the travel time of the lowest floor (lowest basement $\mathrm{OE}$ level) is treated as a reference 

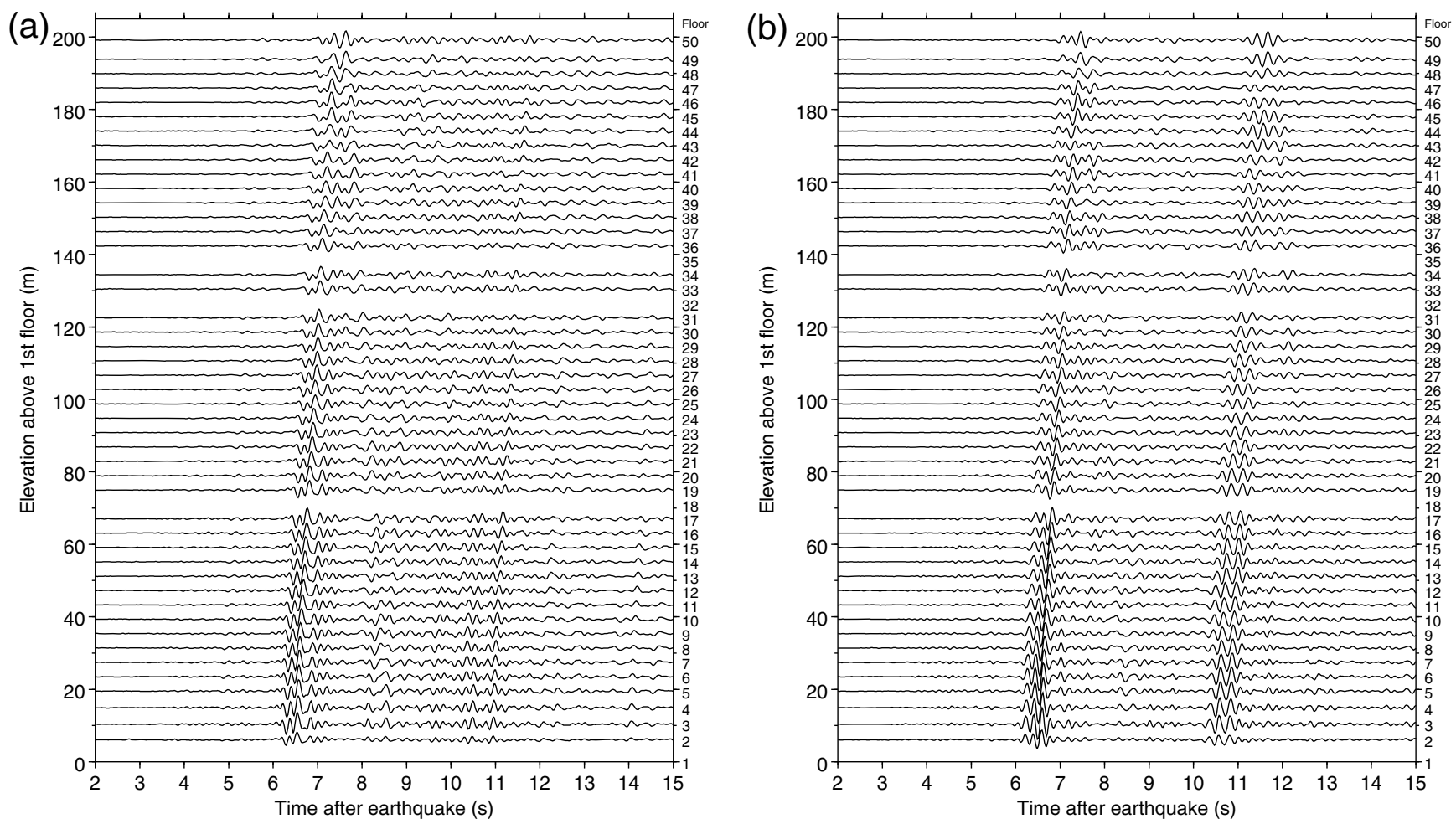

Figure 2. The 52-story building acceleration responses on the building's low-cost Community Seismic Network sensors to the 3 May $2015 M_{\mathrm{L}} 3.8$ Baldwin Hills, California, earthquake (distance = $10.9 \mathrm{~km}$ ). (a) East-west horizontal accelerations; (b) north-south horizontal accelerations. All time series were band-pass filtered $0.1-10 \mathrm{~Hz}$. Amplitudes are normalized by a constant (400 m/g) to show amplitudes as a function of floor height relative to ground level (in meters) and to show relative floor-to-floor amplitudes. Floors for which data are not shown either had no installed sensor or had a faulty sensor recording at the time of the earthquake.

value because this is the theoretical receiver nearest the earthquake-excitation source location. The travel time to all other floors is then computed via cross correlation using level $\mathrm{OE}$ as the reference; the time lag at maximum correlation represents the travel time from $0 \mathrm{E}$ to other floors. For the second travel-time measurement method, an undamaged wave propagation scenario is compared floor by floor with a damaged case. The relative travel time is measured as the lag time at maximum cross correlation of each floor's preand postdamage record. A window of one wavelength is used in the cross-correlation reference waveform to avoid contamination from reflected waves. The result will be near zero below the damage and will accumulate through the damage to a constant value above the damaged floors (Fig. 3). The results shown in the Results section use travel times computed with the second method, although the subsequent analysis is identical regardless of which method is used to compute travel time. We discuss both travel-time calculation methods for completeness, but we only apply the second method here because it is more suitable for three reasons. First, the reflected phase(s) created by the damaged floor(s) can make correlation with a reference lowermost floor waveform unstable. Second, the wavelength of the upgoing wave changes depending on the width and strength of the damage scenario, creating bias when using the lowermost floor as the reference. Finally, real applications of this methodology will be applied to buildings containing existing sensor arrays that can be used to characterize an undamaged response.

The derivative of the travel time at a specific floor is calculated with respect to that floor's elevation; this is simply the spatial gradient of the relative travel time. This gradient is then used to compute the narrowband-filtered shear-wave velocities using equation (13) in one dimension only

$$
\frac{1}{c^{2}(\mathrm{z})}=\left|\frac{\partial \tau(z)}{\partial z}\right|^{2}-\frac{1}{A(z) \omega^{2}} \frac{\partial^{2} A(z)}{\partial z^{2}}
$$

in which $c$ is the phase velocity, $A$ is the amplitude, $\tau$ is the travel time, $z$ is the vertical direction coordinate, and $\omega$ is the angular frequency. The first term on the right side is the contribution from the spatial travel-time gradient, and the second term is the amplitude correction which accounts for finitefrequency effects such as interference or backscattering. For the present application, the finite-frequency effects are generally negligible in the examined frequency ranges. The maximum effect of this term is $0.4 \%$ in the scenarios examined; nevertheless, we use the full solution (equation 15). Because the gradient of the relative travel times is negligible except on damaged floors, a constant gradient of $200 \mathrm{~m} / \mathrm{s}$ is added to prevent division by zero when we take the reciprocal to measure phase velocities. This reference velocity is chosen because it is the approximate velocity of a shear wave 
Table 1

Damage Scenarios

\begin{tabular}{|c|c|c|}
\hline Scenario & Group Name & Residual Stiffness \\
\hline 1 & Braces 20-24 & 0.001 \\
\hline 2 & Braces 25-29 & 0.001 \\
\hline 3 & Braces 30-34 & 0.001 \\
\hline 4 & Braces 35-39 & 0.001 \\
\hline 5 & Braces $40-44$ & 0.001 \\
\hline 6 & Braces 20-24 & 0.1 \\
\hline 7 & Braces 25-29 & 0.1 \\
\hline 8 & Braces 30-34 & 0.1 \\
\hline 9 & Braces 35-39 & 0.1 \\
\hline 10 & Braces 40-44 & 0.1 \\
\hline 11 & Braces 20-24 & 0.5 \\
\hline 12 & Braces 25-29 & 0.5 \\
\hline 13 & Braces 30-34 & 0.5 \\
\hline 14 & Braces 35-39 & 0.5 \\
\hline 15 & Braces $40-44$ & 0.5 \\
\hline 16 & Braces 20-24 & 0.8 \\
\hline 17 & Braces 25-29 & 0.8 \\
\hline 18 & Braces 30-34 & 0.8 \\
\hline 19 & Braces 35-39 & 0.8 \\
\hline 20 & Braces $40-44$ & 0.8 \\
\hline 21 & Braces 20 and 21 & 0.001 \\
\hline 22 & Braces 30 and 31 & 0.001 \\
\hline 23 & Braces 40 and 41 & 0.001 \\
\hline 24 & Braces 20 and 21 & 0.1 \\
\hline 25 & Braces 30 and 31 & 0.1 \\
\hline 26 & Braces 40 and 41 & 0.1 \\
\hline 27 & Braces 20 and 21 & 0.5 \\
\hline 28 & Braces 30 and 31 & 0.5 \\
\hline 29 & Braces 40 and 41 & 0.5 \\
\hline 30 & Braces 20 and 21 & 0.8 \\
\hline 31 & Braces 30 and 31 & 0.8 \\
\hline 32 & Braces 40 and 41 & 0.8 \\
\hline 33 & Brace 25 & 0.001 \\
\hline 34 & Brace 35 & 0.001 \\
\hline 35 & Brace 45 & 0.001 \\
\hline 36 & Brace 25 & 0.1 \\
\hline 37 & Brace 35 & 0.1 \\
\hline 38 & Brace 45 & 0.1 \\
\hline 39 & Brace 25 & 0.5 \\
\hline 40 & Brace 35 & 0.5 \\
\hline 41 & Brace 45 & 0.5 \\
\hline 42 & Brace 25 & 0.8 \\
\hline 43 & Brace 35 & 0.8 \\
\hline 44 & Brace 45 & 0.8 \\
\hline 45 & Braces 25, 45 & 0.001 \\
\hline 46 & Braces 25, 35 & 0.001 \\
\hline 47 & Braces 25 and 45 & 0.1 \\
\hline 48 & Braces 25 and 35 & 0.1 \\
\hline 49 & Braces 25 and 45 & 0.5 \\
\hline 50 & Braces 25 and 35 & 0.5 \\
\hline 51 & Braces 25 and 45 & 0.8 \\
\hline 52 & Braces 25 and 35 & 0.8 \\
\hline 53 & Braces 25 and 45 & $0.001,0.0005$ \\
\hline 54 & Braces 25 and 45 & $0.0005,0.001$ \\
\hline 55 & Braces 25 and 45 & $0.1,0.05$ \\
\hline 56 & Braces 25 and 25 & $0.05,0.1$ \\
\hline 57 & Braces 25 and 45 & $0.5,0.25$ \\
\hline 58 & Braces 25 and 45 & $0.25,0.5$ \\
\hline 59 & Braces 25 and 45 & $0.8,0.4$ \\
\hline 60 & Braces 25 and 45 & $0.4,0.8$ \\
\hline
\end{tabular}

Residual stiffness $=1.0-(\%$ loss of stiffness $) / 100$. For example, 0.2 residual stiffness $=80 \%$ loss of stiffness. through the undamaged building (Clayton et al., 2015). Although arbitrary, this choice of reference velocity does not affect the analysis because it is applied after the measurements are made; it is solely done for numerical stability. The final result is a map of velocity as a function of both frequency and distance (floor). Because there is a downgoing reflected wave from the top of the building that interferes with the upgoing wave, this analysis fails for the top few floors. Near the top of the building, the two waves overlap and interfere (e.g., Fig. 3a), confounding the calculation of both travel time and amplitude. Because of this, we omit the imaging results above $200 \mathrm{~m}$ (floor 47) in the results that follow.

Adding Seismic Noise. To mimic a real earthquake signal, we add noise to the synthetic data before the computation of the travel time. We use real data from the CSN accelerometer array in the 52 -story building, selecting a random 80 -s period from the month of January 2017. For each floor, we use exactly the same time period, so that synchronous noise time series recorded at each actual floor are applied. Using the same time period for each floor, we purposely keep intact any causal signals in the noise, which might bias the analysis. We set the signal-to-noise ratio to 7 , a reasonable value for a local earthquake signal. This would be conservative for a large earthquake signal, as even the small-magnitude $M_{\mathrm{L}} 3.8$ local earthquake records from this building shown in Figure 2 indicate. Large-amplitude earthquake excitation would be expected to strongly dominate over the background environmental and instrumental noise. Although the addition of the noise has a pronounced effect on the raw waveforms (Figs. 4a-8a), the frequency-dependent travel-time measurement is not significantly affected below $10 \mathrm{~Hz}$. This is because of the relatively high-frequency content of the noise relative to the simulated earthquake signal. Above $12 \mathrm{~Hz}$, the high amplitude of the noise relative to the earthquake signal precludes measurement of travel times via cross correlation. Below $1 \mathrm{~Hz}$, the corresponding wavelengths are much larger than the interstory distance, making it difficult to localize a traveling wave. Thus, we restrict our analysis to $1-12 \mathrm{~Hz}$.

\section{Results}

Scenario damage simulations using the technique described were computed for 60 damage states (shown in Table 1). In each, a damage state was introduced at single or multiple building floors by reducing the axial stiffness of the brace members in the model in both the north-south and eastwest directions. Axial stiffness was reduced by a specified amount (Table 1) to simulate buckling of the brace members at those levels. The result is a decrease in member stiffness (but not mass), which is the quantity directly responsible for variations in wave travel times and seismic velocities used in the tomographic imaging process.

Examples of the undamaged-state and damaged-state wave velocity mapping procedure and results are shown in Figures 4-8 computed from the numerical simulations for 

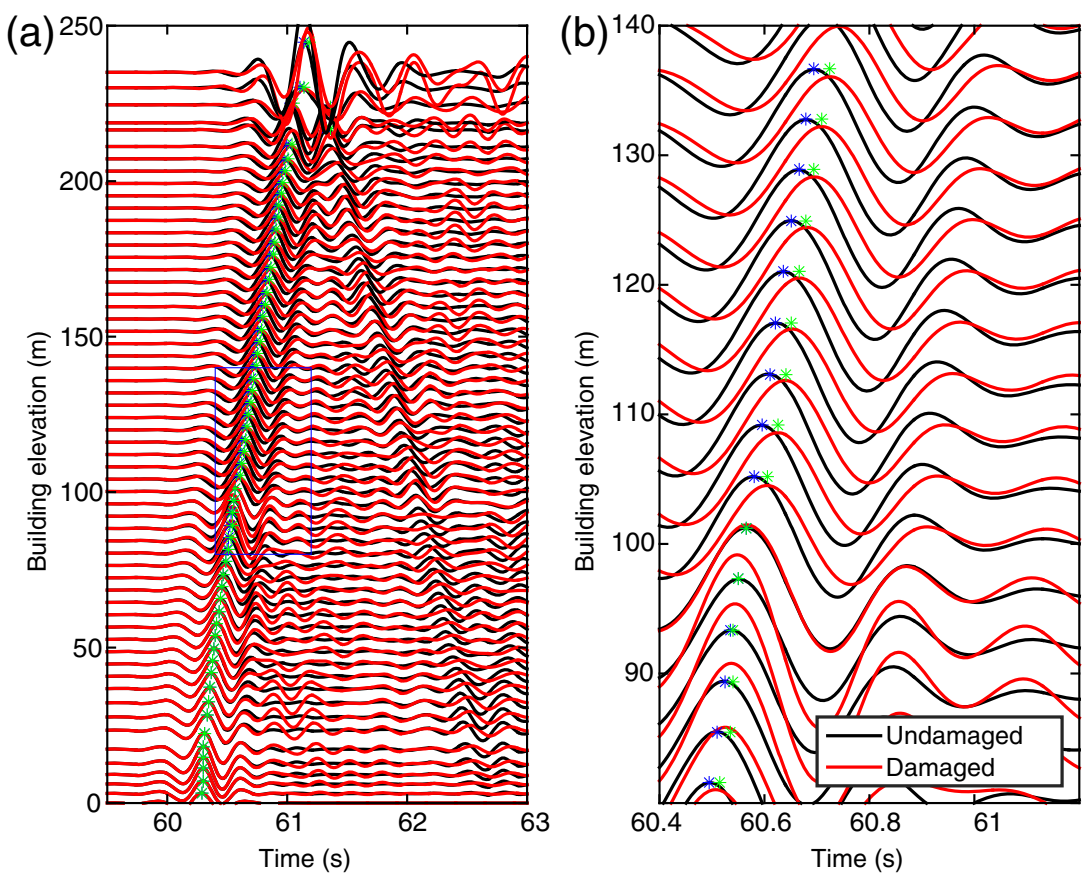

Figure 3. (a) Illustration of the cross correlation of damaged and undamaged waveforms for scenario 24 (see Table 1). The first-arriving waveforms are nearly identical below the damage $(\sim 95 \mathrm{~m})$ but accrue a delay above the damage. In addition, there is a reflection from the damaged floors. Asterisks show the time of maximum cross-correlation value between the two waveforms at each floor and the maximum amplitude of the undamaged case for reference. (b) A zoomed-in view within the box shown on the left. There is no measured delay time between the two cases until just above the damaged floors; this shows that the reflected phase does not influence the travel-time calculation using this method. Building elevations are relative to lowermost " $0 \mathrm{E}$ " level (fifth subbasement). The color version of this figure is available only in the electronic edition.

shown in Figure 4. The seismic velocities (Fig. 4e) show a clear decrease for floors 40-44 (elevations 185-200 m) across all frequencies between 1 and $12 \mathrm{~Hz}$. Anomalous energy shows up for high frequencies on some floors.

Scenario 24 (Table 1) shows results for a $90 \%$ brace stiffness reduction applied to floors 20 and 21 . The displacement waveforms and velocity mapping results for this scenario are shown in Figure 5. The seismic velocities (Fig. 5e) show a clear decrease for floors 20 and 21 (elevations 95-105 m) across all frequencies between 1 and $12 \mathrm{~Hz}$. Anomalous energy shows up for high frequencies on some floors.

Scenario 27 (Table 1) shows results for a $50 \%$ brace stiffness reduction applied to floors 20 and 21 . The displacement waveforms and velocity mapping results for this scenario are shown in Figure 6. The seismic velocities (Fig. 6e) show a clear decrease for floors 20 and 21 (elevations 95-105 m) across all frequencies between 1 and $12 \mathrm{~Hz}$. This is similar to scenario 24 except that the velocity decrease is smaller in amplitude, as expected.

Scenario 30 (Table 1) shows results for a $20 \%$ brace stiffness reduction applied to floors 20 and 21 . The displacement waveforms and velocity mapping results

our theoretical seismic array. Here, we present results for scenarios 15, 24, 27, 39, and 45 (see Table 1). We chose these scenarios to discuss because they represent different levels and spatial distributions of damage. Other similar cases to those presented can be expected to look similar. For example, scenarios 13 and 14 can be expected to look similar and analogous to scenario 15 .

Figures $4 a-8$ a show the simulated waveforms with noise added for five different damage scenarios. Figures $4 \mathrm{~b}-\mathrm{e}$ to $8 \mathrm{~b}-\mathrm{e}$ show the results of the imaging procedure. In each of these figures, panel (b) shows the relative travel time as a function of frequency and building elevation, calculated by cross-correlating waveforms with the undamaged case. Panel (c) shows the amplitude (second term on the right side of equation 15) of the filtered waveforms measured as the maximum of the envelope function. Panel (d) shows the spatial gradient of the relative travel time (first term of the right side of equation 15), and panel (e) shows the seismic velocity measured by applying equation (15). In each scenario, the imaging results were produced blindly; the imaging team had no prior knowledge of the damage scenario.

Scenario 15 (Table 1) shows results for a $50 \%$ brace stiffness reduction applied to floors 40-44. The displacement waveforms and velocity mapping results for this scenario are for this scenario are shown in Figure 7. The seismic velocities (Fig. 7e) no longer show a clear decrease for floors 20 and 21. The stiffness decrease is too small to detect and image and does not show up in the raw waveforms, which look essentially identical to the undamaged case.

Finally, scenario 49 (Table 1) shows results for a $50 \%$ brace stiffness reduction for floors 25 and 45 . The displacement waveforms and velocity mapping results for this scenario are shown in Figure 8. The seismic velocities (Fig. 8e) show a small but visible velocity decrease for floors 25 and 45 (elevations 120 and $195 \mathrm{~m}$ ).

Overall, the travel time of the upgoing wave relative to the undamaged case is constant as expected until the direct wave encounters the region in which damage has been imposed through the broken brace connections. Complications in the traveling wave are present near the top of the building, likely because of the interference of the direct and reflected waves. This is particularly obvious for travel-time measurements at low frequencies for our theoretical array simulations. As discussed earlier, the amplitude of the noise at frequencies above $12 \mathrm{~Hz}$ is larger than that of the earthquake signal.

Broadband and narrowband anomalies are present in the velocity images (Figs. 4b-e to 8b-e) occurring over floors both below and above the floors containing the assigned stiffness anomaly. This is a secondary effect, however; the 
(a)

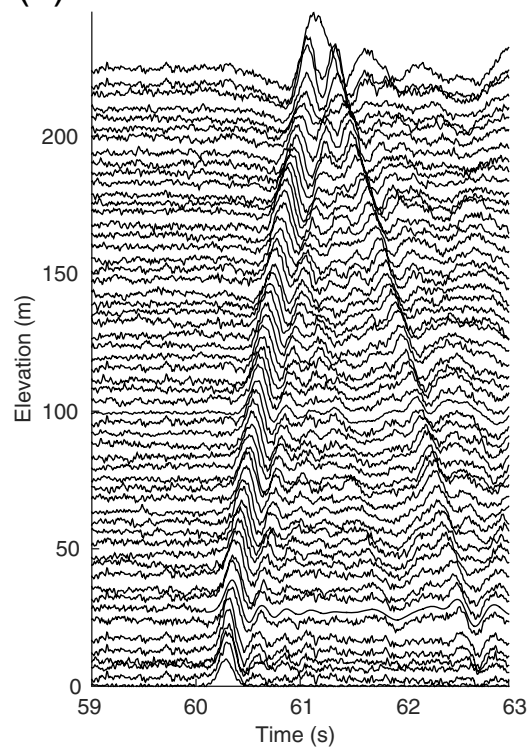

(b)

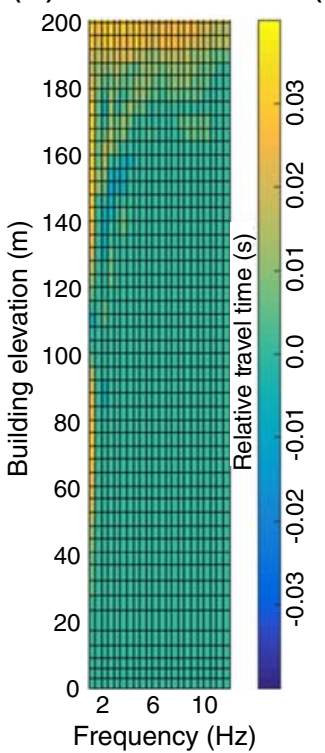

(c)

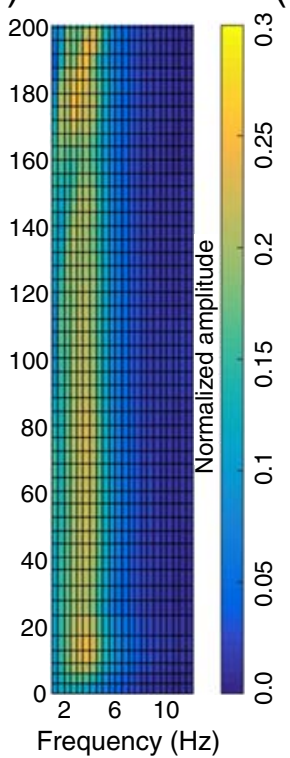

(d)

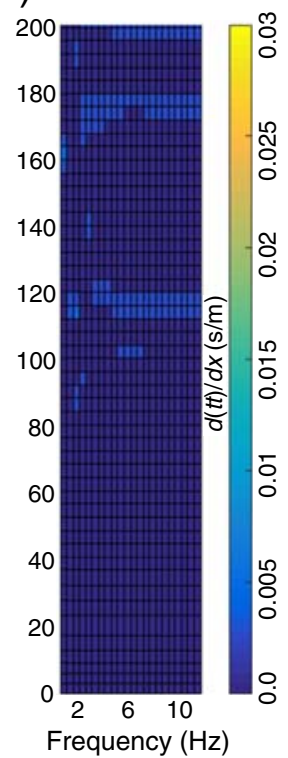

(e)

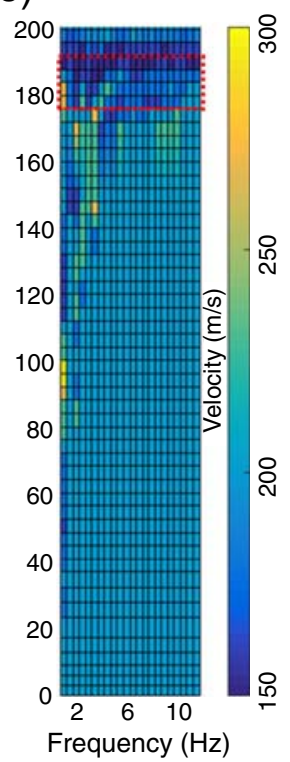

Figure 4. Imaging process and results for scenario 15 (see Table 1). (a) Broadband simulated displacement seismograms for scenario 15 (see Table 1) with noise added. The target signal (the propagating wave) has longer wavelength than the noise; therefore, the noise has a relatively small impact on the imaging results below $12 \mathrm{~Hz}$. The top floor waveforms have been omitted so that their large amplitudes do not swamp out the details in the floors below. (b) Relative travel time as a function of frequency and building elevation calculated by crosscorrelating waveforms with the undamaged case. (c) Amplitude measured as the maximum of the envelope function. (d) The spatial gradient of the relative travel time $d(t t) / d x$. (e) The seismic velocity measured by applying equation (15). Although there is some scatter, the damaged portion of the building is clearly imaged at elevations 175-191 m (dotted box). Building elevations are relative to lowermost 0E level (fifth subbasement). The color version of this figure is available only in the electronic edition.

(a)

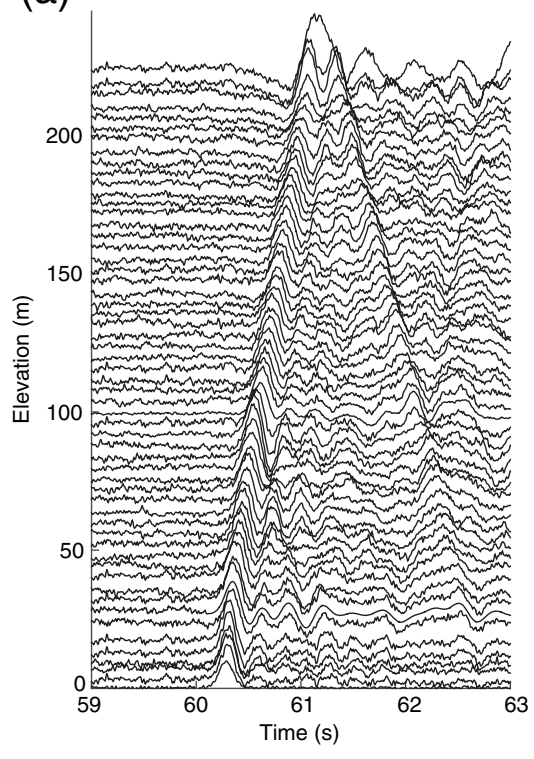

(b)

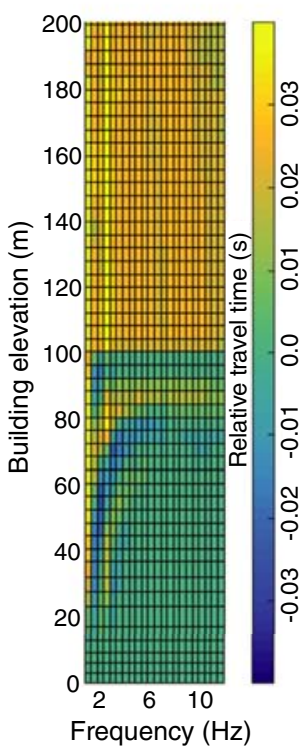

(c)

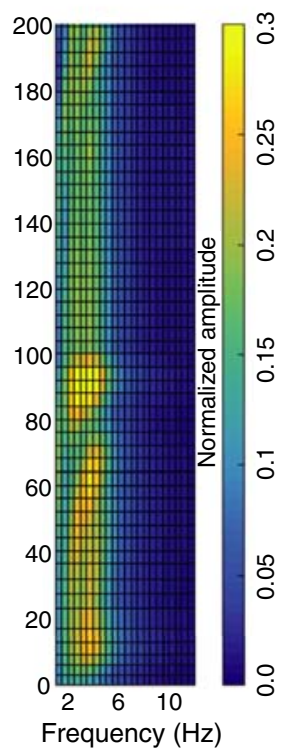

(d)

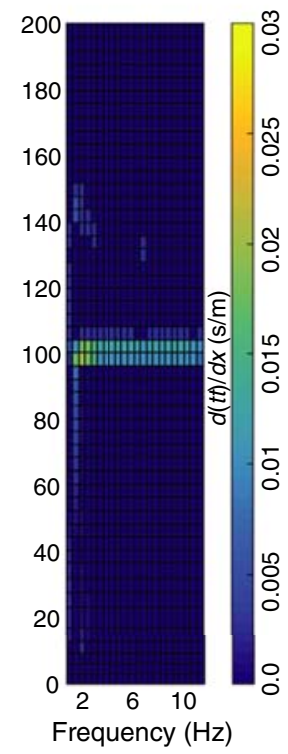

(e)

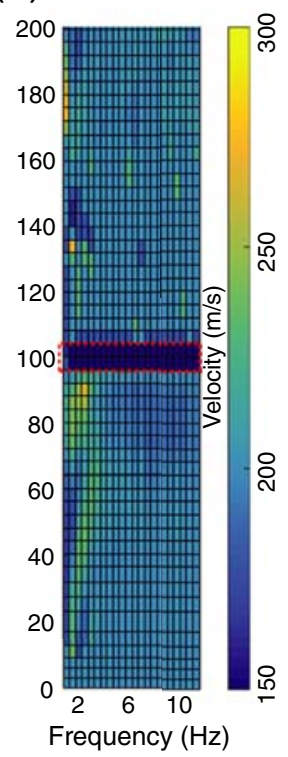

Figure 5. Same as Figure 4, applied to scenario 24 (see Table 1). The damaged portion was successfully imaged between 96 and $100 \mathrm{~m}$ (dotted box). The color version of this figure is available only in the electronic edition.

primary velocity change because the imposed stiffness change is the strongest feature in the images. There is residual anomalous contamination in the velocity results for the floors directly below where damage is introduced, for example, the vertical oscillations in velocities in Figure 5e between elevations 10$90 \mathrm{~m}$ for frequencies between 1 and $3 \mathrm{~Hz}$. We believe this may be caused by the production of new resonant modes that are the result of the low-velocity damaged region (the reduced 
(a)

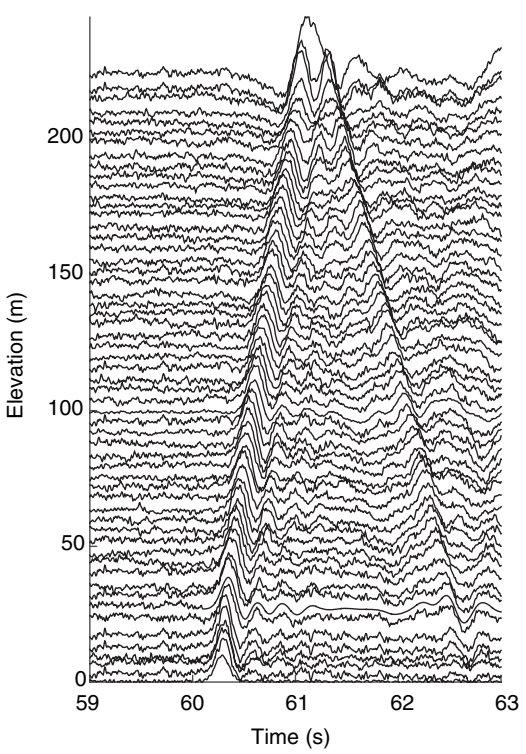

(b)

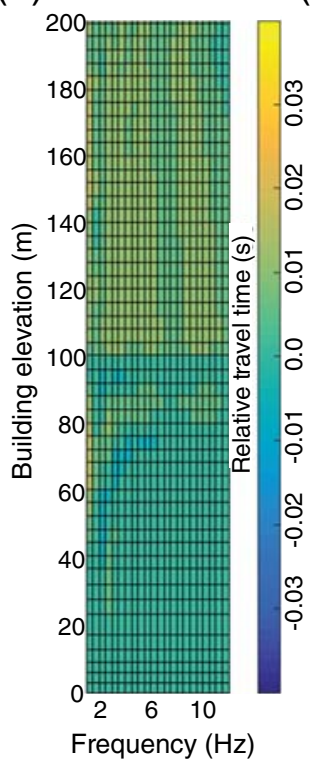

(c)

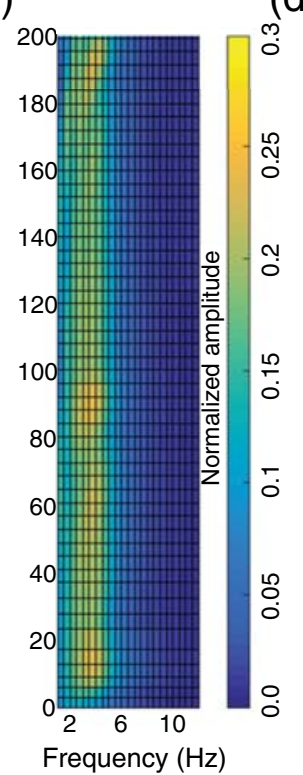

(d)

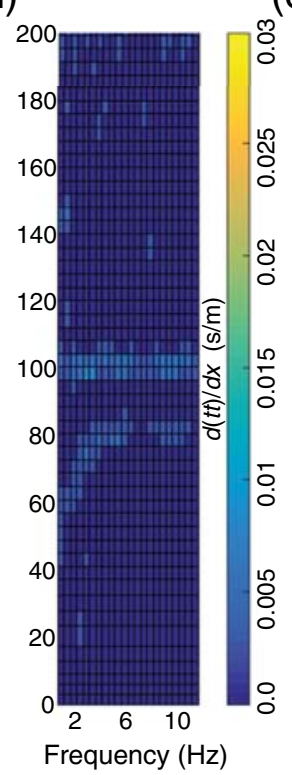

(e)

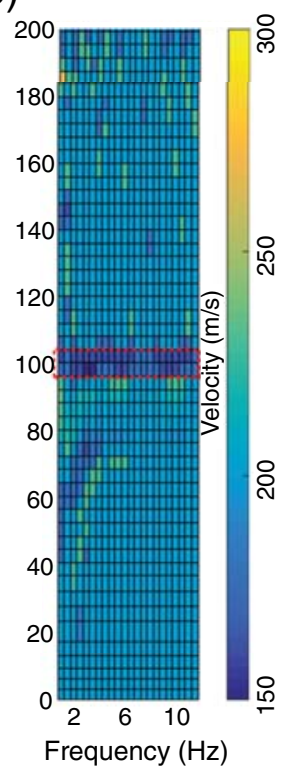

Figure 6. Same as Figure 4, applied to scenario 27 (see Table 1). The damage is similar but lower in amplitude to scenario 24 shown in Figure 5 (dotted box). The color version of this figure is available only in the electronic edition.

(a)

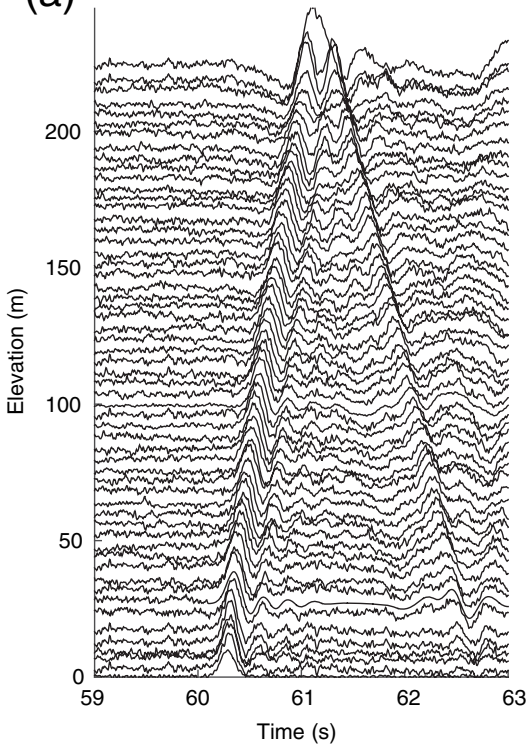

(b)

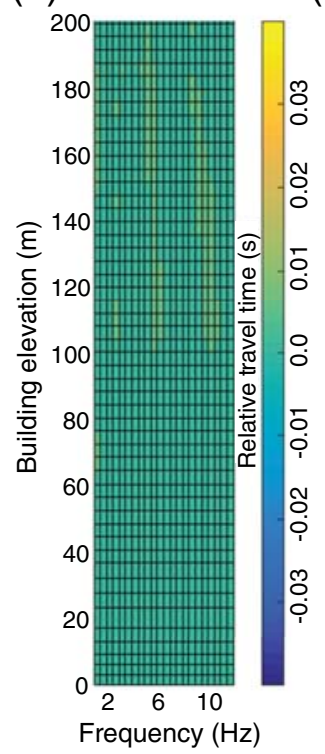

(c)

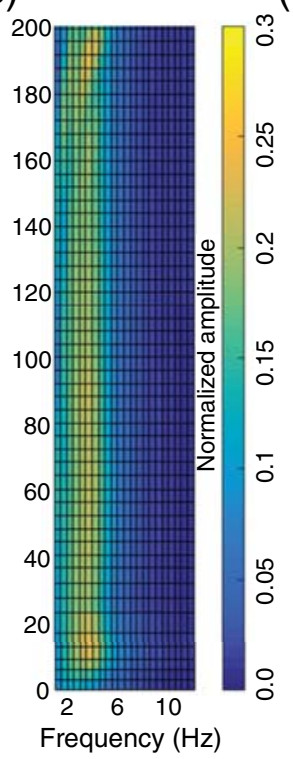

(d)

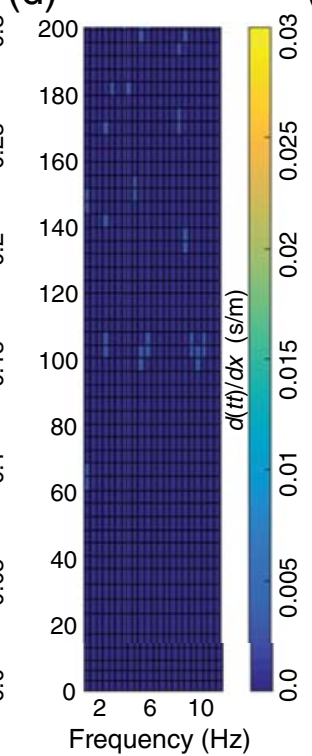

(e)

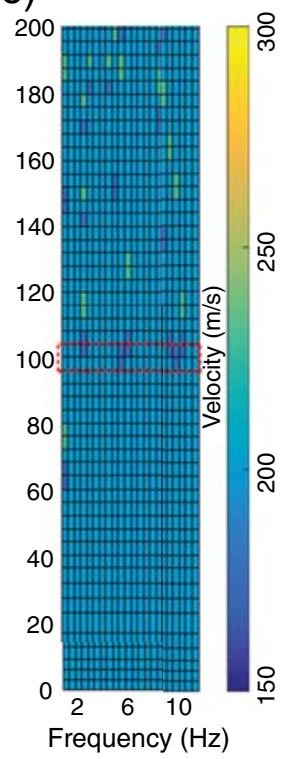

Figure 7. Same as Figure 4, applied to scenario 30 (see Table 1). The damage is too small to detect and image (dotted box). The color version of this figure is available only in the electronic edition.

stiffness layers). The travel times of these new resonant modes have positive and negative polarities that suggest the sensitivity of the new modes to floors underlying the damage. This is analogous to dispersive phases observed in fault zones (e.g., Lewis and Ben-Zion 2010) and sedimentary basins (e.g. Roten and Fäh, 2007), which are discrete low-velocity zones within shallow crustal Earth structure. Although this result complicates our interpretation of the method presented here, it also suggests an additional feature in the waveforms that could be used to identify damage. See the (E) electronic supplement for a description of additional damage scenario velocity imaging tests that were conducted to estimate the spatial resolving power as a function of location.

Alternatively, these anomalies may be explained by interference between the upgoing direct wave with downgoing reflected waves from midlevel floors. Internal gradients likely exist in both the pre- and postdamage buildings, for example, caused by changes in the overall footprint of the building at 
(a)

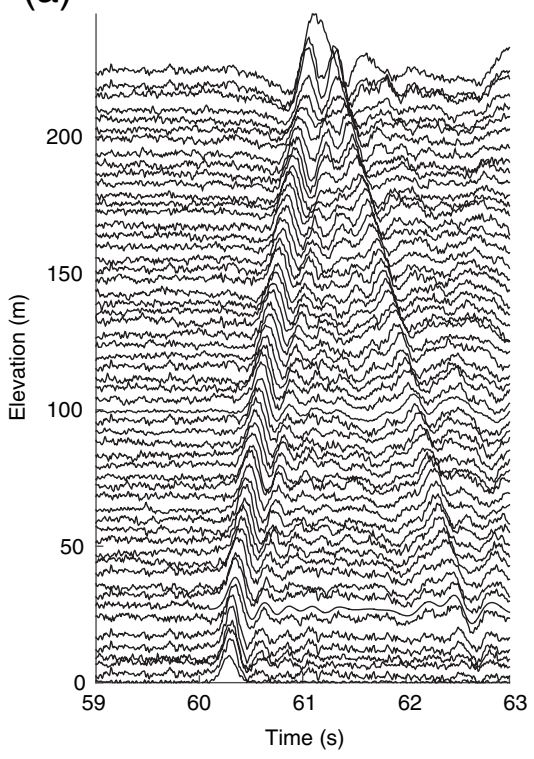

(b)

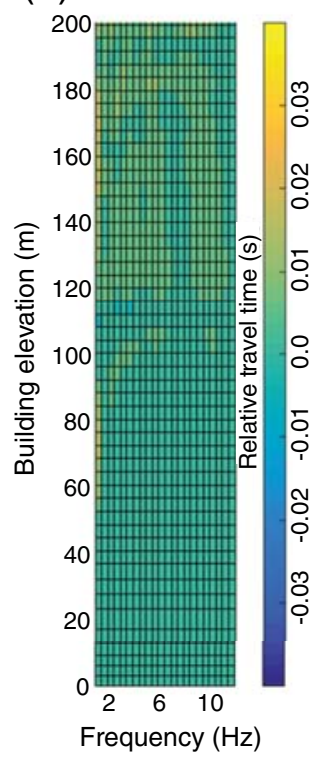

(c)

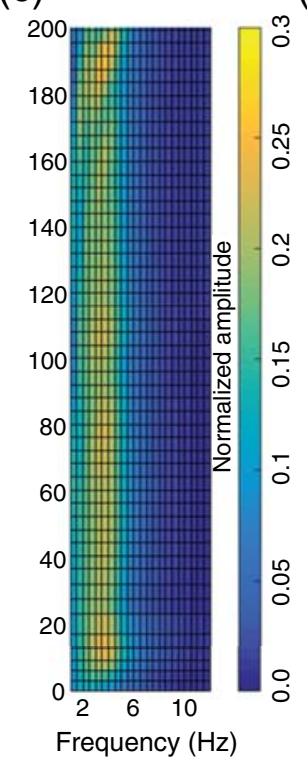

(d)

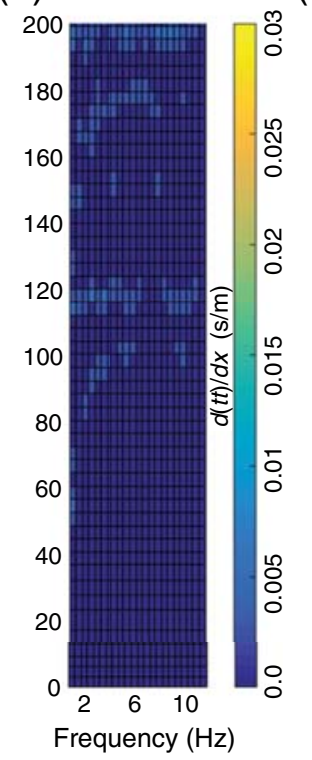

(e)

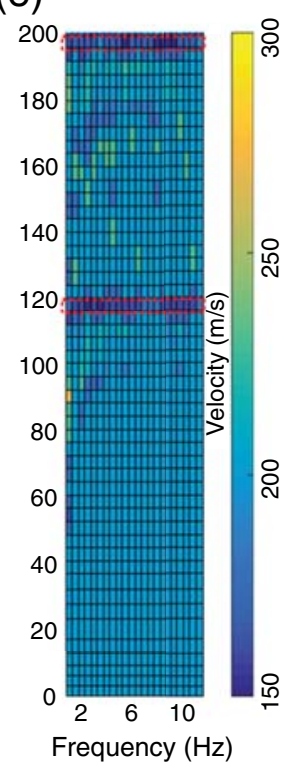

Figure 8. Same as Figure 4, applied to scenario 49 (see Table 1). Two different damaged floors, at 116 and $175 \mathrm{~m}$, are clearly imaged (dotted boxes). The color version of this figure is available only in the electronic edition.

a particular upper-level floor. Just below the impedance contrast, the wave amplitude can vary because of the opposite polarities in the upgoing and downgoing legs at a fixed-fixed boundary impedance contrast. At the fixed-free surface reflection level, amplitude polarities of upgoing and downgoing waves are the same, resulting in doubling of the amplitude at the top of the building when it is excited by earthquake motions at the base. In Figures 4a-8a, we omitted the top floor waveforms so that their large amplitudes do not swamp the details in the floors below.

The narrowband anomalies seen in Figures 4e-8e are likely the result of higher noise levels in the high-frequency content of the wave signals. Earthquake signals have decreasing amplitude above a corner frequency controlled by the earthquake size (Stein and Wysession, 2009), but the seismic noise in downtown Los Angeles contains strong anthropogenic and wind signals at higher frequencies. In these test cases, the noise amplitude begins to dominate the signal at $10 \mathrm{~Hz}$, confounding travel-time measurements of the earthquake waves. Although apparent in all of the test scenarios, these erroneous measurements are restricted in frequency and are thus distinguishable from the broadband low-velocity regions induced by the damage. In general, this suggests that the lower frequency $(<10 \mathrm{~Hz})$ excitation of earthquakes will produce clearer signals at lower frequency bands than the characteristic noise of the building.

Comparing Figures 4 and 6 in which the stiffness reduction is the same for both scenarios, the velocity reduction is stronger for 50\% stiffness reduction in floors 40-44 (scenario 15, Fig. 4) than for $50 \%$ reduction in floors 20 and 21 (scenario 27, Fig. 6). This illustrates how the damage detectability is dependent on location. The stiffness of the structure is largely controlled by the interplay between the dual lateral system (i.e., the moment frames and the braced frames), which varies vertically. Although the 50\% reduction of stiffness in the braced frames is similar in both scenarios 15 and 27, the net absolute difference in the total stiffness of the floor is not. This makes comparisons of equivalent damage in one component of the lateral system at different levels of the building complicated because constant damage to any floor's braces does not result in constant overall absolute stiffness change for every floor. The lower levels of damage detection imaged for scenario 27 (compared with scenario 15) is likely attributable to the larger overall absolute stiffness of these floors (20 and 21) under the same amount of brace damage compared with the stiffness of the upper floors (40-44). The stiffness of the moment frame relative to the braced frame at the top of the building is lower, resulting in a larger wavespeed change at the top for the same level of damage to the braces.

This points to several limitations of this approach. A general understanding of the lateral resisting system is needed to know how to interpret velocity changes in terms of absolute values in stiffness reduction. In addition, the locations of potential damage are indicated by constant velocity reductions across the entire bandwidth. The bandlimited velocity reductions are indirectly related to the damage region in that they may be new resonant-mode signatures induced by the lowvelocity regions. Anisotropy can arise from asymmetry in building geometry and material type, and our method should be able to resolve anisotropy by studying the polarities of the propagating waves. Resolution of damage will be reduced at the lowest floors, but this can be overcome if the seismic array is extended to the ground outside the building. Finally, although one of the benefits of this approach is the independence from a modal coordinate system, the resolution of the mapping results is dependent on the spatial sampling level of the sensors. 


\section{Conclusions}

The properties of solutions to the Helmholtz equation are used to develop a propagating wave solution approach to detecting damage in buildings via waveform feature extraction immediately after a major earthquake. Representing a building as a continuum leads to application of Helmholtz tomography to image gradients in elastic properties, resulting in localized higher spatial resolution of damage occurrence. Low-cost MEMS technology sensors are now making it possible to instrument buildings on a floor-by-floor scale, recording continuous vibration data at high sample rates, motivating the application of this method. The Helmholtz equation provides a straightforward way to solve for seismic-velocity variations in a building whose pre- and postdamage states have been determined by vibration time series recorded on dense seismic arrays. This study uses simulated linear response data from a test bed building consisting of a 52-story ( +5 basement levels) steel moment and braced-frame system. This building provides an opportunity to test the potential damage signatures in waveforms of buckling and tension rupture of the braced frame components.

Helmholtz tomographic imaging is applied to more than 60 imposed damage scenarios to a finite-element model of the 52 -story test bed building. In each, a damage state is introduced by reducing the axial stiffness of the brace members in the model in both the north-south and east-west directions to simulate buckling of the brace members at those levels. Travel times of simulated propagating waves through the undamaged and damaged structures are computed by crosscorrelating all floors with the lowest-level reference floor. The derivative of the travel time is then calculated with respect to each floor's elevation. This spatial gradient is used to compute the narrowband-filtered shear-wave velocities using the Helmholtz equation. The final result is a map of velocity as a function of both frequency and vertical distance (floor). Actual recorded noise is added to the synthetic data before the computation of the travel time.

The velocity change attributable to stiffness gradient is the strongest feature in the shear-wave velocity maps and indicates where the damage was imposed in the finite-element model. Secondary mapping effects that are also present include velocity features that may be the result of the production of new modes that result from the stiffness contrast that comprises a new internal boundary condition. Alternatively, these variations may be explained by interference between the upgoing direct wave with downgoing reflected waves from midlevel floors. Noise amplitude begins to dominate the signal above $10 \mathrm{~Hz}$ restricting interpretation to frequencies below that; the characteristic building noise, however, is distinguishable from the broadband low-velocity regions induced by the damage. In general, these results suggest that broadband excitation of earthquakes will produce timedomain signals within a wide range of building resonant frequencies that may be useful for damage detection.

\section{Data and Resources}

The dynamic analysis ETABS output data are available upon request by emailing kohler@caltech.edu. ETABS software is distributed by Structural and Earthquake Engineering Software, Computers and Structures, Inc., Berkeley, California (http://www.csiberkeley.com; http://docs.csiamerica.com/ manuals/etabs/Analysis\%20Reference.pdf, last accessed July 2018). Center for Engineering Strong Motion Data, available at http://www.strongmotioncenter.org (last accessed January 2018).

\section{Acknowledgments}

The authors thank the Terrestrial Hazard Observation and Reporting (THOR) Center at Caltech and the Divisions of Geological and Planetary Science, and Engineering and Applied Science at Caltech for funding research connected with the Community Seismic Network. A. A. and F. L. were supported by National Science Foundation (NSF) Grant CyberSEES1442665 and the King Abdullah University of Science and Technology (KAUST) under Award OCRF-2014-CRG3-2300. The authors are grateful to Nori Nakata and German Prieto for their thoughtful and careful reviews of this article.

\section{References}

Aki, K. (1972). Scaling law of earthquake source time-function, Geophys. J. Int. 31, nos. 1/3, 3-25.

Aki, K., and P. G. Richards (1980). Quantitative Seismology, W. H. Freeman and Company, New York, New York.

Allam, A. A., Y. Ben-Zion, I. Kurzon, and F. Vernon (2014). Seismic velocity structure in the Hot Springs and Trifurcation areas of the San Jacinto fault zone, California, from double-difference tomography, Geophys. J. Int. 198, no. 2, 978-999.

Ben-Zion, Y., F. L. Vernon, Y. Ozakin, D. Zigone, Z. E. Ross, H. Meng, M. White, J. Reyes, D. Hollis, and M. Barklage (2015). Basic data features and results from a spatially dense seismic array on the San Jacinto fault zone, Geophys. J. Int. 202, no. 1, 370-380.

Brenguier, F., M. Campillo, C. Hadziioannou, N. M. Shapiro, R. M. Nadeau, and E. Larose (2008). Postseismic relaxation along the San Andreas fault at Parkfield from continuous seismological observations, Science 321, 1478-1481, doi: 10.1126/science.1160943.

Celebi, M. (2006). Recorded earthquake responses from the integrated seismic monitoring network of the Atwood Building, Anchorage, Alaska, Earthq. Spectra 22, no. 4, 847-864, doi: 10.1193/1.2359702.

Chopra, A. K. (2001). Dynamics of Structures: Theory and Applications to Earthquake Engineering, Second Ed., Prentice Hall, Upper Saddle River, New Jersey, 844 pp.

Clayton, R., T. Heaton, M. Chandy, A. Krause, M. Kohler, J. Bunn, M. Olson, M. Faulkner, M. Cheng, L. Strand, et al. (2011). Community Seismic Network, Ann. Geophys. 54, 6, doi: 10.4401/ag-5269.

Clayton, R. W., T. Heaton, M. Kohler, M. Chandy, R. Guy, and J. Bunn (2015). Community Seismic Network: A dense array to sense earthquake strong motions, Seismol. Res. Lett. 86, 1354-1363, doi: $10.1785 / 0220150094$.

Dunand, F., J. E. Rodgers, A. V. Acosta, M. Salsman, P.-Y. Bard, and M. Celebi (2004). Ambient vibration and earthquake strong-motion data sets for selected USGS extensively instrumented buildings, U.S. Geol. Surv. Open-File Rept. 2004-1375, 31 pp.

Farrar, C. R., and K. Worden (2007). An introduction to structural health monitoring, Phil. Trans. Roy. Soc. Lond. A 365, no. 1851, 303-315.

Farrar, C. R., and K. Worden (2012). Structural health monitoring: A machine learning perspective, First Ed., John Wiley and Sons Ltd, Hoboken, New Jersey, doi: 10.1002/9781118443118. 
Farrell, J., R. B. Smith, S. Husen, and T. Diehl (2014).Tomography from 26 years of seismicity revealing that the spatial extent of the Yellowstone crustal magma reservoir extends well beyond the Yellowstone caldera, Geophys. Res. Lett. 41, no. 9, 3068-3073.

French, S., V. Lekic, and B. Romanowicz (2013). Waveform tomography reveals channeled flow at the base of the oceanic asthenosphere, Science 342, no. 6155, 227-230.

Hall, J., T. Heaton, M. Halling, and D. Wald (1995). Near-source ground motion and its effects on flexible buildings, Earthq. Spectra 11, 569-605.

Hillers, G., P. Roux, M. Campillo, and Y. Ben-Zion (2016). Focal spot imaging based on zero lag cross-correlation amplitude fields: Application to dense array data at the San Jacinto fault zone, J. Geophys. Res. 121, 8048-8067, doi: 10.1002/2016JB013014.

Hirose, T., H. Nakahara, and T. Nishimura (2017). Combined use of repeated active shots and ambient noise to detect temporal changes in seismic velocity: Application to Sakurajima volcano, Japan, Earth Planets Space 69, no. 1, 42, doi: 10.1186/s40623-017-0613-7.

Kohler, M. D., T. H. Heaton, and S. C. Bradford (2007). Propagating waves recorded in the steel, moment-frame Factor building during earthquakes, Bull. Seismol. Soc. Am. 97, 1334-1345

Kohler, M. D., T. H. Heaton, and M. H. Cheng (2013). The Community Seismic Network and Quake-Catcher Network: Enabling structural health monitoring through instrumentation by community participants, Proc. of the SPIE Smart Structures/Non-destructive Evaluation Conference, San Diego, California, 10-14 March 2013.

Kohler, M. D., T. H. Heaton, M. H. Cheng, and P. Singh (2014). Structural health monitoring through dense instrumentation by community participants: The Community Seismic Network and Quake-Catcher Network, 10th U.S. National Conf. on Earthquake Engineering (NC1OEE), Anchorage, Alaska, 21-25 July 2014.

Kohler, M. D., A. Massari, T. H. Heaton, H. Kanamori, E. Hauksson, R. Guy, R. W. Clayton, J. Bunn, and K. M. Chandy (2016). Downtown Los Angeles 52-story high-rise and free-field response to an oil refinery explosion, Earthq. Spectra 32, no. 3, 1793-1820, doi: 10.1193/ 062315EQS101M.

Koulakov, I., E. I. Gordeev, N. L. Dobretsov, V. A. Vernikovsky, S. Senyukov, A. Jakovlev, and K. Jaxybulatov (2013). Rapid changes in magma storage beneath the Klyuchevskoy group of volcanoes inferred from timedependent seismic tomography, J. Volcanol. Geoth. Res. 263, 75-91.

Lay, T., and T. C. Wallace (1995). Modern Global Seismology, Academic Press, San Diego, California.

Lecocq, T., C. Caudron, and F. Brenguier (2014). MSNoise, a python package for monitoring seismic velocity changes using ambient seismic noise, Seismol. Res. Lett. 85, no. 3, 715-726.

Lewis, M. A., and Y. Ben-Zion (2010). Diversity of fault zone damage and trapping structures in the Parkfield section of the San Andreas fault from comprehensive analysis of near fault seismograms, Geophys. J. Int. 183, no. 3, 1579-1595, doi: 10.1111/j.1365-246X.2010.04816.x.

Lin, F.-C., and M. H. Ritzwoller (2011). Helmholtz surface wave tomography for isotropic and azimuthally anisotropic structure, Geophys. J. Int. 186, doi: 10.1111/j.1365-246X.2011.05070.x.

Lin, F.-C., D. Li, R. W. Clayton, and D. Hollis (2013). High-resolution 3D shallow crustal structure in Long Beach, California: Application of ambient noise tomography on a dense seismic array, Geophysics 78, no. 4, Q45-Q56, doi: 10.1190/geo2012-0453.1.

Lin, F.-C., M. H. Ritzwoller, and R. Snieder (2009). Eikonal tomography: Surface wave tomography by phase front tracking across a regional broad-band seismic array, Geophys. J. Int. 177, 1091-1110, doi: 10.1111/j.1365-246X.2009.04105.x.

Lin, G., P. M. Shearer, R. S. Matoza, P. G. Okubo, and F. Amelung (2014). Three-dimensional seismic velocity structure of Mauna Loa and Kilauea volcanoes in Hawaii from local seismic tomography, J. Geophys. Res. 119, no. 5, 4377-4392.

Mahin, S. A. (1998). Lessons from damage to steel buildings during the Northridge earthquake, Eng. Struct. 20, nos. 4/6, 261-270.

Mordret, A., H. Sun, G. A. Prieto, M. N. Toksöz, and O. Büyüköztürk (2017). Continuous monitoring of high-rise buildings using seismic interferometry, Bull. Seismol. Soc. Am. 107, no. 6, 2759-2773, doi: $10.1785 / 0120160282$.

Nakata, N., and R. Snieder (2014). Monitoring a building using deconvolution interferometry. II: Ambient vibration analysis, Bull. Seismol. Soc. Am. 104, no. 1, doi: 10.1785/0120130050.

Nakata, N., R. Snieder, S. Kuroda, S. Ito, T. Aizawa, and T. Kunimi (2013). Monitoring a building using deconvolution interferometry, I: Earthquake-data analysis, Bull. Seismol. Soc. Am. 103, no. 3, 16621678, doi: $10.1785 / 0120120291$.

Nakata, N., W. Tanaka, and Y. Oda (2015). Damage detection of a building caused by the 2011 Tohoku-Oki earthquake with seismic interferometry, Bull. Seismol. Soc. Am. 105, no. 5, 2411-2419, doi: 10.1785/0120140220.

Porritt, R. W., R. M. Allen, D. C. Boyarko, and M. R. Brudzinski (2011). Investigation of Cascadia segmentation with ambient noise tomography, Earth Planet. Sci. Lett. 309, no. 1, 67-76.

Prieto, G. A., J. F. Lawrence, A. I. Chung, and M. D. Kohler (2010). Impulse Response of Civil Structures from Ambient Noise Analysis, Bull. Seismol. Soc. Am. 100, no. 5A, 2322-2328, doi: 10.1785/0120090285.

Rodgers, J. E., and M. Celebi (2005). A proposed method for the detection of steel moment connection fractures using high-frequency, transient accelerations, U.S. Geol. Surv. Open-File Rept. 2005-1375, 88 pp.

Rodgers, J. E., and S. A. Mahin (2004). Effects of connection hysteretic degradation on the seismic behavior of steel moment-resisting frames, PEER Report 2003/13, Pacific Earthquake Engineering Research Center, University of California, Berkeley.

Rodgers, J. E., and S. A. Mahin (2009). Local fracture-induced phenomena in steel moment frames, Earthq. Eng. Struct. Dynam. 38, 135-155.

Roeder, C. W. (2000). State of the art report on connection performance, FEMA Tech. Rept. 355D, Federal Emergency Management Agency, Washington, D.C.

Roten, D., and D. Fäh (2007). A combined inversion of Rayleigh wave dispersion and 2-D resonance frequencies, Geophys. J. Int. 168, no. 3, 1261-1275, doi: 10.1111/j.1365-246X.2006.03260.x.

Saygin, E., and B. L. N. Kennett (2012). Crustal structure of Australia from ambient seismic noise tomography, J. Geophys. Res. 117, no. B1, doi: 10.1029/2011JB008403.

Shapiro, N. M., M. Campillo, L. Stehly, and M. H. Ritzwoller (2005). Highresolution surface-wave tomography from ambient seismic noise, Science 307, no. 5715, 1615-1618.

Shearer, P. (1999). Introduction to Seismology, Cambridge University Press, Cambridge, Massachusetts.

Snieder, R., and E. Safak (2006). Extracting the building response using interferometric imaging; theory and application to the Millikan Library in Pasadena, California, Bull. Seismol. Soc. Am. 96, 586-598.

Stein, S., and M. Wysession (2009). An Introduction to Seismology, Earthquakes, and Earth Structure, Second Ed., John Wiley \& Sons, Hoboken, New Jersey.

Sun, H., A. Mordret, G. A. Prieto, M. N. Toksöz, and O. Büyüköztürk (2017). Bayesian Characterization of buildings using seismic interferometry on ambient vibrations, Mech. Syst. Signal Process. 85, 468-486.

Taira, T., A. Nayak, and F. Brenguier (2015). Temporal variability in seismic velocity at the Salton Sea geothermal field, AGU Fall Meeting Abstracts, Abstract ID S41B-2753.

Taranath, B. S. (1997). Steel, Concrete, and Composite Design of Tall Buildings, Second Ed., McGraw-Hill, San Francisco, California.

Ulusoy, H. S., K. Banga, and E. Kalkan (2013). Real-time seismic monitoring of Veterans Affairs hospital buildings, Proc. of SPIE-The International Society for Optical Engineering, Vol. 8692, 86920I, doi: 10.1117/12.2012236.

Updike, R. E. (1996). USGS response to an urban earthquake-Northridge '94, U.S. Geol. Surv. Open-File Rept. 96-263, 78 pp.

Ward, K. M., R. C. Porter, G. Zandt, S. L. Beck, L. S. Wagner, E. Minaya, and H. Tavera (2013). Ambient noise tomography across the Central Andes, Geophys. J. Int. 194, no. 3, 1559-1573, doi: 10.1093/gji/ggt166.

Youssef, N. F. G., D. Bonowitz, and J. L. Gross (1995). A survey of steel moment-resisting frame buildings affected by the 1994 Northridge earthquake, National Institute of Standards and Technology, NISTIR 562. 
Department of Mechanical and Civil Engineering

California Institute of Technology

MC 104-44

Pasadena, California 91125

(M.D.K.)

Department of Geology and Geophysics

University of Utah

Frederick Albert Sutton Building

115 S 1460 E, Room 383

Salt Lake City, Utah 84112-0102

(A.A., F.-C.L.)
Department of Civil, Environmental and Geodetic Engineering

The Ohio State University

470 Hitchcock Hall

2070 Neil Avenue

Columbus, Ohio 43210

(A.M.) 